\title{
Complex relationship between SAPO framework topology, content and distribution of Si and catalytic behaviour in the MTO reaction
}

\author{
I. Pinilla-Herrero ${ }^{\mathrm{a}, \mathrm{b}}$, C. Márquez-Álvarez ${ }^{\mathrm{a}}$, and E. Sastre ${ }^{\mathrm{a}}$ \\ Three small-pore silicoaluminophosphates containing relatively large cavities in their structure (LEV, LTA and SAV) have been \\ hydrothermally synthesized with various silicon concentrations. The effect of the silicon content and distribution on both \\ the physicochemical and the catalytic properties of the SAPO molecular sieves was studied. Remarkable differences in the \\ Si incorporation were found, showing that the topological features and the structure directing agent employed in each case \\ play an important role, controlling not just the Si location in the framework, but also the amount of Si incorporated. In all \\ the cases, the formation of Si islands, associated to stronger acid sites, was favoured by the use of higher concentrations of \\ the $\mathrm{Si}$ source in the synthesis gel. However, it has been found that framework topology can have greater influence than \\ acidity on the catalytic behaviour of SAPO materials in the MTO transformation.
}

\section{Introduction}

The possibility of converting methanol into hydrocarbons (MTH) was discovered by Mobil Oil Company in $1976,{ }^{1}$ and has been widely investigated since then. This zeolite-catalyzed reaction was initially considered a new route for the procurement of high quality gasoline, but further investigations revealed that it is possible to selectivity obtain almost any kind of hydrocarbon from methanol (from light olefins to gasoline or aromatics) selecting an appropriate catalyst and the correspondent optimal reaction conditions. ${ }^{2-4}$ Thus, considering the versatility of products that is possible to obtain, the MTH technology has had a high impact, and forty years after its discovery keeps being an attractive topic for both academic and industrial researchers. The versatility of this technology is not restricted to the products, and also applies to the reactants since methanol can be produced from several carbon sources such as: coal, natural gas, biomass or even $\mathrm{CO}_{2} \cdot{ }^{5-8}$

Among the wide range of hydrocarbons that is possible to obtain from methanol, short chain olefins are specially demanded since they constitute one of the most important petrochemical intermediates, and actually the methanol to olefins (MTO) technology is ready for commercialization ${ }^{5,9}$ and first production plants were set up in China in 2010. Small-pore silicoaluminophosphate (SAPO) molecular sieves can be efficiently used as MTO catalysts, providing exceptionally high selectivities to C2-C4 olefins. Specifically, SAPO-34, with CHA topology, is known to be an active and selective catalyst, and it is the most interesting from the point of view of the industrial operation of the MTO plants. ${ }^{10}$ However, SAPO catalysts suffer a relatively fast deactivation under reaction conditions. The complex reaction and deactivation mechanism of $\mathrm{MTH}$ transformation has been widely studied. ${ }^{3,11-15}$ According to the proposed dual cycle hydrocarbon pool mechanism, ${ }^{16}$ the process is an autocatalytic reaction and both alkene and aromatic intermediates are involved forming two inter-related cycles in which the methylation and cracking or dealkylation reactions lead to the formation of light alkenes. In a further step, the reaction between methanol and the hydrocarbon

\footnotetext{
a. Instituto de Catálisis y Petroleoquímica, CSIC. C/ Marie Curie, 2. 28049 Madrid, Spain.

b. Department of Chemistry, University of Oslo, Blindern, Oslo 0315, Norway.

+ Corresponding authors Emails: esastre@icp.csic.es and c.marquez@icp.csic.es
}

intermediates or the combination of such intermediates would lead to the formation of large molecules that are not able to diffuse out of the catalyst and keep retained in the porous structure forming carbonaceous deposits (coke) that may block the access of methanol to the active centres or hinder the diffusion of reaction products, resulting in the deactivation of the catalysts. ${ }^{17-20}$ Coke formation has also been attributed to the presence of formaldehyde molecules, formed by hydrogen transfer reactions between methanol molecules, and an increase of the catalyst time life has been found when using dimethyl ether as reactant instead of methanol. ${ }^{13,21}$

Since the fast deactivation is the main drawback of SAPO materials as catalysts for the MTO transformation, great efforts have been devoted to the optimization of the physicochemical properties of SAPO-34 in order to improve its catalytic performance. ${ }^{4,22-26}$ Extensive studies indicate that there are some key parameters to be controlled in order to improve the properties of SAPO materials as MTO catalysts. In this sense, the particle size and the presence of hierarchical porosity have been widely correlated with the diffusion limitations in the micropores, showing that smaller or mesopore-modified crystals exhibit an enhanced stability in the process. $22,23,27-30$ Other parameter that strongly affects the catalytic performance is the acidity of the materials. This property depends on the content and distribution of silicon in the SAPO framework; considering the Si distribution as the kind of $\mathrm{Si}$ environments formed. Thus, the number and strength of acid sites formed will be dependent on both the Si content and distribution. Some authors have reported on the effect of the silicon content in the catalytic performance of SAPO catalysts. ${ }^{31-34}$

The framework of microporous aluminophosphates is built up of $\mathrm{AlO} 4$ and $\mathrm{PO} 4$ tetrahedra connected through the oxygen atoms in an alternating arrangement. SAPO materials are formed by the isomorphous substitution of trivalent $\mathrm{Al}$ and pentavalent $\mathrm{P}$ atoms by tetravalent $\mathrm{Si}$ atoms. The incorporation of Si can take place following different mechanisms, so that it is possible to generate multiple Si environments. When a silicon atom is incorporated in a phosphorous position, a Si(4Al) environment is formed. This substitution mechanism, known as $\mathrm{SM} 2$, generates a negative charge in the lattice that, if compensated by a proton, would lead to the formation of a bridging Si-OH-Al hydroxyl group that exhibits Brønsted acidity. However, Si can be also incorporated into the framework by pairs in the so-called substitution mechanism SM3, in which two silicon atoms simultaneously substitute a pair of adjacent $\mathrm{Al}$ and 
$P$ atoms. This kind of substitution does not alter the framework charge neutrality, so it does not result in the generation of Brønsted acid sites. Therefore, the concentration of Brønsted acid sites in SAPO materials can be equal to the total Si content or smaller, depending on the kind of incorporation. In most cases, the incorporation of $\mathrm{Si}$ into the AIPO4 framework takes place by SM2 or a combination of SM2 and SM3 mechanisms, in a way that prevents the formation of unstable Si-O-P bonds. Thereby, every SiO4 tetrahedron can be linked to $\mathrm{n} \mathrm{AlO4}$ tetrahedra and 4-n SiO4 tetrahedra (with $n=0-4$ ), so Si atoms can have up to 5 different $\mathrm{Si}(\mathrm{nAl})$ environments. It has been proposed that the acid strength of the Si-OH-Al group associated to a given $\mathrm{Si}(\mathrm{nAl})$ site in SAPO materials increases as $\mathrm{n}$ decreases. ${ }^{35-38}$ In this way, both the concentration and the strength of acid sites are determined by the overall $\mathrm{Si}$ substitution mechanism.

As mentioned before, the acidic properties of SAPO-34 and the influence of such properties in the behaviour of the material as catalysts in the methanol to olefins transformation have been widely investigated. However, screening and optimization of the acidic properties of many other SAPO materials potentially applicable as MTO catalysts have received much less attention so far. In this contribution we investigate the effect of the silicon content and distribution on both the physicochemical and the catalytic properties of three small-pore silicoaluminophosphates with large cavities in their structure and pore structures similar to that of SAPO-34: SAPO-35 (LEV), STA-7 (SAV) and SAPO-42 (LTA). The effect of the topological differences of these materials in the deactivation and products distribution in the MTO process has been previously investigated. ${ }^{39}$ Here, we explore how the modification of the physicochemical properties might improve the catalytic performance of these molecular sieves.

\section{Experimental}

\section{Synthesis of SAPO molecular sieves}

All the materials reported in this work were synthesized by a hydrothermal method. The preparation of the synthesis gels and the crystallization conditions were as follows:

- SAPO-35 was prepared following the same procedure reported elsewhere, ${ }^{40,41}$ from gels with molar composition 1 $\mathrm{Al}_{2} \mathrm{O}_{3}: 1 \mathrm{P}_{2} \mathrm{O}_{5}: x \mathrm{SiO}_{2}: 1.5 \mathrm{HMI}: 55 \mathrm{H}_{2} \mathrm{O}$, crystallized at $473 \mathrm{~K}$ for $24 \mathrm{~h}$. According to such procedure, aluminium hydroxide hydrate (Sigma-Aldrich) was dispersed in deionized water using one third of the total weight of water, and an aqueous solution (34 wt\%) of orthophosphoric acid (Sigma-Aldrich, 85\%) was slowly added to the suspension. The mixture was vigorously stirred for $2 \mathrm{~h}$ before adding fumed silica (Aerosil 200, Degussa) along with the remaining amount of water. After around $30 \mathrm{~min}$, the structure directing agent hexamethyleneimine (HMI, SigmaAldrich, 99\%) was added dropwise and the mixture was stirred for about $4 \mathrm{~h}$ to obtain a uniform gel.

- STA-7 was prepared adapting the experimental procedure followed by $\mathrm{M}$. Castro et al. ${ }^{42} \mathrm{Gels}$ with molar composition 1 $\mathrm{Al}_{2} \mathrm{O}_{3}: 0.75 \mathrm{P}_{2} \mathrm{O}_{5}: x \mathrm{SiO}_{2}: 0.25 \mathrm{TEAOH}: 0.125$ Cyclam : $55 \mathrm{H}_{2} \mathrm{O}$ were prepared using $\mathrm{H}_{3} \mathrm{PO}_{4}$ (Sigma-Aldrich, 85\%), $\mathrm{Al}(\mathrm{OH})_{3}$ (Sigma-Aldrich) and $\mathrm{SiO}_{2}$ (Aerosil 200, Degussa) as sources of the framework elements. 1,4,8,11-tetraazacyclotetradecane (cyclam, Sigma-Aldrich, 98\%) and tetraethylammonium hydroxide (TEAOH, Sigma-Aldrich, 35\% aqueous solution) were used as structure directing agents, acting in the synthesis as cotemplates. The reactants were combined in the order: water, acid, aluminium hydroxide, silica, cyclam and TEAOH. The resulting mixture was stirred for $1 \mathrm{~h}$ in order to gain a homogeneous gel. Crystallization was carried out at $463 \mathrm{~K}$ for $48 \mathrm{~h}$.

SAPO-42 samples were prepared from gels with molar composition $1 \mathrm{Al}_{2} \mathrm{O}_{3}: 1 \mathrm{P}_{2} \mathrm{O}_{5}: \times \mathrm{SiO}_{2}: 0.066 \mathrm{TMAOH}: 1.74$ DEA : $0.34 \mathrm{HF}: 92 \mathrm{H}_{2} \mathrm{O}$, using tetramethylammonium hydroxide (TMAOH, Sigma-Aldrich, 25\% aqueous solution) and diethanolamine (DEA, Alfa Products, 98\%) as structure directing agents. The precursor compounds of the solid framework elements were fumed silica (Aerosil 200, Degussa), pseudoboehmite (PURAL SB-1, Sasol), and orthophosphoric acid (Sigma-Aldrich, 85\%). Hydrofluoric acid (Sigma-Aldrich, 48\%) was used to add the fluoride ions necessary to obtain pure LTA crystals. In a typical synthesis, two mixtures were prepared in two different beakers. Mixture A contained $50 \%$ of the total water, the required amount of orthophosphoric acid, alumina and silica. Mixture $B$ was composed of the remaining water, the structure directing agents (TMAOH and DEA) and the hydrofluoric acid. Both mixtures were stirred separately for $1 \mathrm{~h}$ before mixture $B$ was slowly added over mixture A. In a final step, the synthesis gel was obtained after 2 more hours under stirring. For crystallization, gels were heated at $423 \mathrm{~K}$ for $168 \mathrm{~h}$. The silicon content in the synthesis gels $(x)$ was varied as indicated in Table 1 in order to crystallize materials with different acidic properties. The homogeneous synthesis gels obtained according to the procedures described above were transferred into teflon-lined stainless steel autoclaves with a capacity of $40 \mathrm{~cm}^{3}$, which were heated in a convection oven at the required temperature and under autogenous pressure for the necessary period of time.

Table 1. Composition of synthesis gels, crystalline phases obtained and composition of calcined SAPO materials.

\begin{tabular}{lcccc}
\hline \multirow{2}{*}{ Sample } & \multicolumn{2}{c}{ Gel composition } & & \multicolumn{2}{c}{$\begin{array}{c}\text { Solid product } \\
\end{array}$} & $\mathrm{x}^{\mathrm{a}}$ & $\mathrm{Si} /(\mathrm{Si}+\mathrm{Al}+\mathrm{P})$ & Phase & $\begin{array}{c}\text { Molar } \\
\text { composition }\end{array}$ \\
\hline S35-0.3E & 0.3 & 0.07 & LEV & $\mathrm{Si}_{0.07} \mathrm{Al}_{0.49} \mathrm{P}_{0.44}$ \\
S35-0.6E & 0.6 & 0.13 & LEV & $\mathrm{Si}_{0.14} \mathrm{Al}_{0.46} \mathrm{P}_{0.40}$ \\
S35-0.8E & 0.8 & 0.17 & LEV & $\mathrm{Si}_{0.18} \mathrm{Al}_{0.44} \mathrm{P}_{0.38}$ \\
STA-0.25E & 0.25 & 0.07 & SAV & $\mathrm{Si}_{0.12} \mathrm{Al}_{0.50} \mathrm{P}_{0.38}$ \\
STA-0.6E & 0.6 & 0.15 & SAV & $\mathrm{Si}_{0.26} \mathrm{Al}_{0.43} \mathrm{P}_{0.31}$ \\
STA-0.8E & 0.8 & 0.19 & SAV & $\mathrm{Si}_{0.30} \mathrm{Al}_{0.42} \mathrm{P}_{0.28}$ \\
S42-0.34A & 0.34 & 0.07 & LTA & $\mathrm{Si}_{0.02} \mathrm{Al}_{0.54} \mathrm{P}_{0.44}$ \\
S42-0.6A & 0.6 & 0.14 & LTA & $\mathrm{Si}_{0.15} \mathrm{Al}_{0.49} \mathrm{P}_{0.36}$ \\
S42-0.8A & 0.8 & 0.17 & LTA & \\
\hline
\end{tabular}

$\mathrm{a} \mathrm{SiO}_{2} / \mathrm{Al}_{2} \mathrm{O}_{3}$ molar ratio

b Sample showing peaks in PXRD pattern not corresponding to LTA phase.

SAPO-35 and STA-7 samples were crystallized under static conditions. Hydrothermal synthesis of SAPO-42 samples was performed using a rotating oven in order to obtain materials with higher crystallinity. The resulting solids were collected by centrifugation and washed with water and ethanol several times and dried at $338 \mathrm{~K}$ overnight. Prior to catalytic testing, the samples were calcined at $823 \mathrm{~K}$ under air flow.

\section{Characterization of the materials}

In order to understand the effect of the changes in the gel composition, the physicochemical properties of the solid materials were studied by several characterization techniques. Powder X-ray diffraction (PXRD) patterns of both as-synthesized and calcined materials were recorded on a PANalytical X'Pert Pro diffractometer using CuK $\alpha$ radiation with a nickel filter. Thermogravimetric analysis (TGA) were done using a PerkinElmer TGA7 instrument to determine the organic content in the as-synthesized samples as well as to verify the complete 
removal of the structure directing agents in the calcined materials. All the TG analyses were carried out under air flow, from 303 to $1173 \mathrm{~K}$ and using a heating rate of $20 \mathrm{~K} / \mathrm{min}$. The crystallite size and morphological features of the silicoaluminophosphates were determined by scanning electron microscopy (SEM) using a Hitachi TM-1000 microscope operated at $15 \mathrm{kV}$ with a solid state backscattering detector (BSE). The textural properties (pore volume and surface area) and adsorption capacity of the calcined samples were determined by nitrogen physisorption at $77 \mathrm{~K}$ employing for the measurements a Micromeritics ASAP 2010 volumetric apparatus. Prior to measurements, samples were degassed at $623 \mathrm{~K}$ under vacuum for $20 \mathrm{~h}$. Chemical analysis ( $\mathrm{Al}, \mathrm{P}$ and $\mathrm{Si}$ ) of the crystalline calcined solids was carried out by inductively coupled plasma optical emission spectroscopy (ICP-OES) using a PerkinElmer 3300DV instrument. For the measurements, samples were dissolved by alkaline fusion. The Si environments formed in the materials were determined by ${ }^{29} \mathrm{Si} \mathrm{CP} / \mathrm{MAS} N \mathrm{NR}$. The spectra were recorded at room temperature in a Bruker AV400-WB spectrometer operating at $79.5 \mathrm{MHz}$ and using a $4 \mathrm{~mm}$ probe spinning at $10 \mathrm{kHz}$. A $\pi / 2$ pulse of $3 \mu \mathrm{s}$, contact time of 6 $\mu$ and recycle delay of $5 \mathrm{~s}$ were used. The chemical shifts were referenced to tetramethylsilane (TMS) that was taken as $0 \mathrm{ppm}$. Ammonia temperature programmed desorption measurements ( $\mathrm{NH}_{3}$-TPD) were performed using a Micromeritics Autochem II chemisorption equipment. In a typical procedure, the sample (100 g of 20-40 mesh pellets) was pre-treated at $827 \mathrm{~K}$ for $1 \mathrm{~h}$ in helium flow $(25 \mathrm{~mL} / \mathrm{min})$ and subsequently cooled to the adsorption temperature $(450 \mathrm{~K})$. A gas mixture of 5.0 vol\% $\mathrm{NH}_{3}$ in He was then flowed over the sample for $4 \mathrm{~h}$ at a rate of 15 $\mathrm{mL} / \mathrm{min}$. Afterwards a $25 \mathrm{~mL} / \mathrm{min}$ helium flow was passed over the sample while maintaining the temperature at $450 \mathrm{~K}$ for 30 min to remove any weakly adsorbed $\mathrm{NH}_{3}$ molecule. Finally, the temperature was increased to $823 \mathrm{~K}$ at a rate of $10 \mathrm{~K} / \mathrm{min}$.

\section{Catalytic testing}

The catalytic tests were carried out at $673 \mathrm{~K}$ and atmospheric pressure using a continuous down flow fixed bed glass reactor with $15 \mathrm{~mm}$ inner diameter. The reactor was fully automated and controlled from a PC (PID Eng\&Tech Microactivity Reference). Nitrogen was used as inert diluent gas at a flow rate controlled by a mass flow controller and methanol was fed as liquid using a Gilson 307 HPLC pump, vaporized and mixed with the nitrogen in a pre-heater at $453 \mathrm{~K}$, generating a gas mixture with a constant methanol/nitrogen ratio of $1 / 1$ mol. Before each reaction, catalysts were pre-treated at $823 \mathrm{~K}$ for $1 \mathrm{~h}$ under air flow in order to remove any traces of water or organic molecules that might be adsorbed in the SAPO pores. The catalyst weight ( $1.0 \mathrm{~g}$ with a pellet size of 20-30 mesh) and the methanol flow rate $(25 \mu \mathrm{L} / \mathrm{min})$ used for each test were adjusted to obtain a WHSV of $1.2 \mathrm{~h}-1$. The reactor effluent stream was analyzed on-line by GC using a Varian CP3800 gas chromatograph equipped with flame ionization (FID) and thermal conductivity (TCD) detectors, using a Petrocol DH5 0.2 capillary column and a Hayesep Q 80-100 mesh packed column for the separation of hydrocarbons and oxygenates, respectively.

\section{Results and discussion}

Influence of the $\mathrm{Si}$ content in the synthesis gel on the physicochemical properties of the SAPO materials.

A series of SAPO materials with different topology and $\mathrm{Si}$ content have been synthesized according to the described experimental procedure. As stated before, samples were prepared with increasing silicon content (Table 1 ) in order to evaluate the effect that this parameter has in the physicochemical properties of the materials, especially regarding the possible formation of different silicon environments in each topology, and trying to define how the silicon content influences the performance of the SAPO catalysts in the MTO reaction.

Powder X-ray diffraction patterns of the as-synthesized samples (Fig. 1) are in good agreement with simulated patterns of framework types LTA (aluminosilicate, zeolite A), SAV (magnesium aluminophosphate, Mg-STA-7) and LEV (aluminosilicate, zeolite levynite) ${ }^{43}$ and previously reported patterns of SAPO- $42^{44}$ STA- $7^{42}$ and SAPO- $35 .{ }^{40}$

These results confirm that it is possible to obtain, SAPO- 35 and STA-7 and SAPO-42 as pure crystalline phases using gel compositions within a wide range of $\mathrm{Si} / \mathrm{Al}$ ratio.
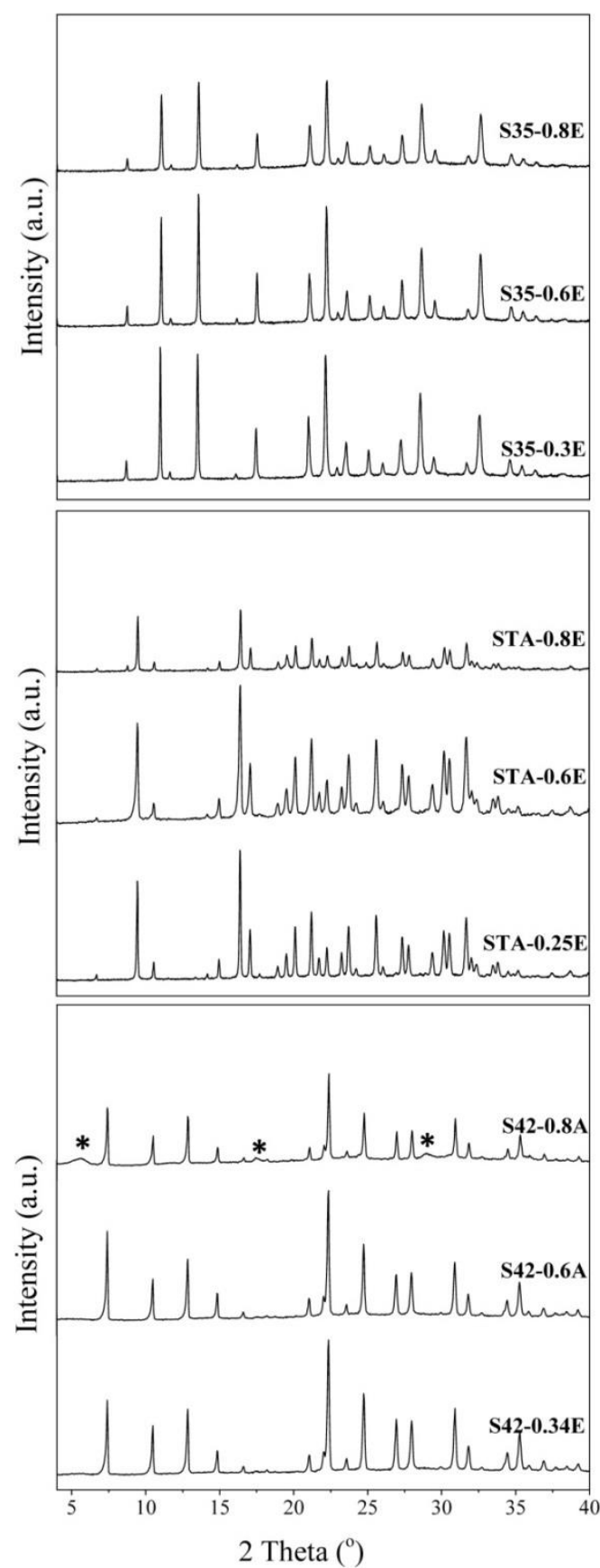

Figure 1. Powder X-ray diffraction patterns of the assynthesized SAPO samples obtained from gels with different $\mathrm{Si}$ concentrations. The asterisks indicate reflections that correspond to an impurity phase. 
Nevertheless it should be noted that the diffractogram of sample S42-0.8A shows three peaks that cannot be ascribed to the LTA phase, which indicates that the SAPO-42 sample obtained from a gel with the highest $\mathrm{Si} / \mathrm{Al}$ ratio $(0.8)$ contains an impurity phase. For this reason, this sample was disregarded from the subsequent studies. It can be also observed that the PXRD patterns of the samples prepared with the highest Si/Al ratio show less intense peaks, indicating a lower crystallinity of these samples. This observation is in good agreement with previous studies, in which the crystallinity of SAPO-35 increased with increasing $\mathrm{Si} / \mathrm{Al}$ ratio up to 0.3 , decreasing progressively for higher Si contents. ${ }^{45}$

The chemical composition of the pure SAPO phases obtained was determined by ICP-OES analysis of the calcined samples (Table 1), in order to evaluate the Si incorporation in the AIPO framework in each topology. In our experience, most of the SAPO samples incorporate $\mathrm{Si}$ easily up to a certain concentration, and normally the molar Si/Al ratios in the solids are close to that from gels. ${ }^{32,41}$ However, the topological differences and the structure directing agent used in the synthesis also play an important role, controlling both the silicon incorporation and the silicon distribution in the framework. ${ }^{46}$ As shown in Table 1 , the silicon content of all SAPO samples increases with the amount of silicon precursor in the synthesis gels, although each framework topology shows different silicon incorporation yield. The $\mathrm{Si} /(\mathrm{Si}+\mathrm{Al}+\mathrm{P})$ molar ratio of the SAPO-35 samples obtained is closed to that of the corresponding synthesis gels in the whole range of $\mathrm{Si}$ content explored. Similar result was obtained for the SAPO-42 sample prepared from a gel with $\mathrm{Si} / \mathrm{Al}$ ratio of 0.6 , whereas the gel with lower Si content led to significantly lower Si incorporation in the solid. In contrast, incorporation of silicon appears to be more favoured in STA-7, as all samples possess a $\mathrm{Si} /(\mathrm{Si}+\mathrm{Al}+\mathrm{P})$ ratio that is around $60-70 \%$ higher than that of their corresponding gels. On the other hand, the changes observed in $\mathrm{Al}$ and $\mathrm{P}$ content of the SAPO materials as the Si content increases indicate also a change on silicon distribution in all samples, as will be discussed below.

After calcination, PXRD patterns showed that all the samples retained their crystalline phases. Practically no loss of crystallinity was observed in the SAPO-35 samples, whereas both SAPO-42 and STA-7 suffered a loss of crystallinity during the calcination process, revealed by a reduction in the intensity of the diffraction peaks (Supporting Information, Fig. S1). Such loss was more pronounced for the samples with higher $\mathrm{Si}$ content. It is plausible to propose that such reduction can be originated by the higher empty space in SAPO-42 and STA-7 samples that possess larger cages in comparison to the Levine cages in SAPO-35. ${ }^{43}$

As it was mentioned previously, the crystal size has been proven to be a key parameter controlling the catalytic behaviour of zeolitic materials in the methanol transformation to olefins, being possible to enhance significantly the stability of the catalysts by decreasing the crystallite size to the nanometer scale. $22,23,27,47$ Besides, it is known for some SAPO materials that the silicon concentration in the synthesis gel influences the size of the obtained crystals. ${ }^{32}$ The crystallite size and morphology of the SAPO samples obtained have been studied by scanning electron microscopy (Fig. 2). As reported before for other silicoaluminophosphates, ${ }^{32}$ both parameters seem to be influenced by the Si content. However there is not a common pattern applicable to the different topologies reported in this work. SAPO-35 crystals exhibit the characteristic rhombohedra morphology, being the samples prepared with higher silicon content slightly smaller in size. The variation of the amount of $\mathrm{Si}$ in the gels also caused changes on the morphology and particle size distribution. With a low Si content, rather uniform rhombohedral crystals were obtained, whereas high Si/Al ratios favoured the formation of multiply twinned crystals, being this effect even more clear in the sample with the highest Si content. This observation is in good agreement with the PXRD results that indicated a lower crystallinity of sample S35-0.8E (Fig. 1).

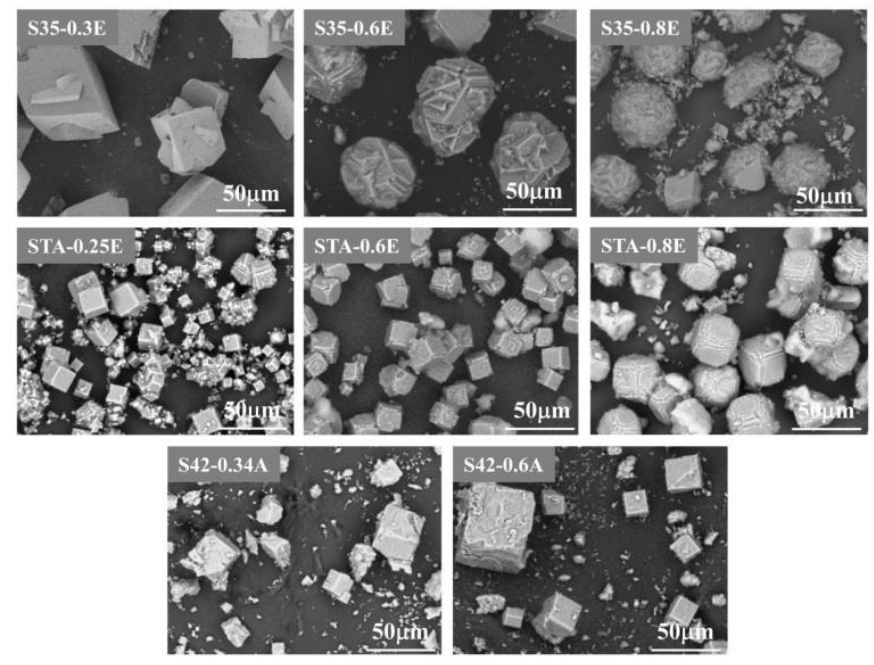

Figure 2. Scanning electron micrographs of the calcined SAPO samples.

For both SAPO-42 and STA-7, the increase in the Si concentration seems to cause a progressive increase in the crystal size. STA-7 samples synthesized with the higher Si/Al ratios (STA-0.6E and STA-0.8E) show a rather narrow particle size distribution with crystal sizes around 20-30 $\mu \mathrm{m}$ in length. On the other hand, the sample prepared with the lowest $\mathrm{Si}$ content (STA-0.25E) has a bimodal crystal size distribution, with a fraction of the crystals of around $10 \mu \mathrm{m}$ and with crystalline agglomerates. The presence of amorphous material detected in the samples gradually increases with increasing $\mathrm{Si}$ content and similarly to the case of SAPO-35, high concentrations of $\mathrm{Si}$ enhance the formation of multiple twinned crystals with irregular edges (Fig. 2). In our experimental conditions, SAPO42 shows the less homogeneous crystal sizes, independently on the Si content in the synthesis gels.

Thermogravimetric analyses (TGA) were carried out aiming to evaluate the incorporation of the organic structure directing agent in the samples. Thermograms of selected samples are plotted in Fig. 3. Different weight loss steps can be observed in the TG profiles depending on the topology and, for each topology, the total amount of organic material retained is dependent on the Si content. In all the cases, there is a first weight loss at temperatures below $450 \mathrm{~K}$ that can be attributed to desorption of adsorbed water. The samples were not pretreated or stored in a controlled atmosphere before the measurements, so the total amount of water that was adsorbed in each case should not be used as an indicator of the hydrophilicity of the samples. The further weight loss steps, registered at higher temperatures, can be associated to the decomposition and desorption of the structure directing agent that is trapped inside the channels of the materials compensating the negative charge associated to the presence of $\mathrm{Si}$ in the framework. Thus, it is initially expected that the organic content is higher in samples with higher Si content, but will be also dependent on the type of $\mathrm{Si}$ incorporation and $\mathrm{Si}$ environments formed in the material. In the case of the SAPO samples studied, the total organic content is not higher at higher Si concentration (Supporting Information, Table S1).

The derivative plots are also presented in Fig. 3 showing the different weight loss steps. In the case of SAPO-35, the weight loss associated with the decomposition and desorption of the organic template is registered at higher temperatures than in 
the other SAPO materials, possibly indicating a restricted diffusion in SAPO-35 or simply that the SDA used for the synthesis in this case is more stabilized in the SAPO cavities (Fig. 3). The weight loss profile of STA-7 is slightly different. There are also two main weight losses associated with the decomposition and desorption of the retained organic molecules, but the desorption temperature is in both cases slightly lower than in SAPO-35. In addition to that, the weight loss registered in the STA-7 samples at around $750 \mathrm{~K}$ is clearly more intense than the one taking place at higher temperatures independently on the Si content. SAPO-42 has at least three steps of weight loss other than the previously mentioned desorption of water. All the weight losses are registered at lower temperatures than in STA7 or SAPO-35. Again, this could be associated with the diffusivity in the material that might be facilitated by the wider pore openings.

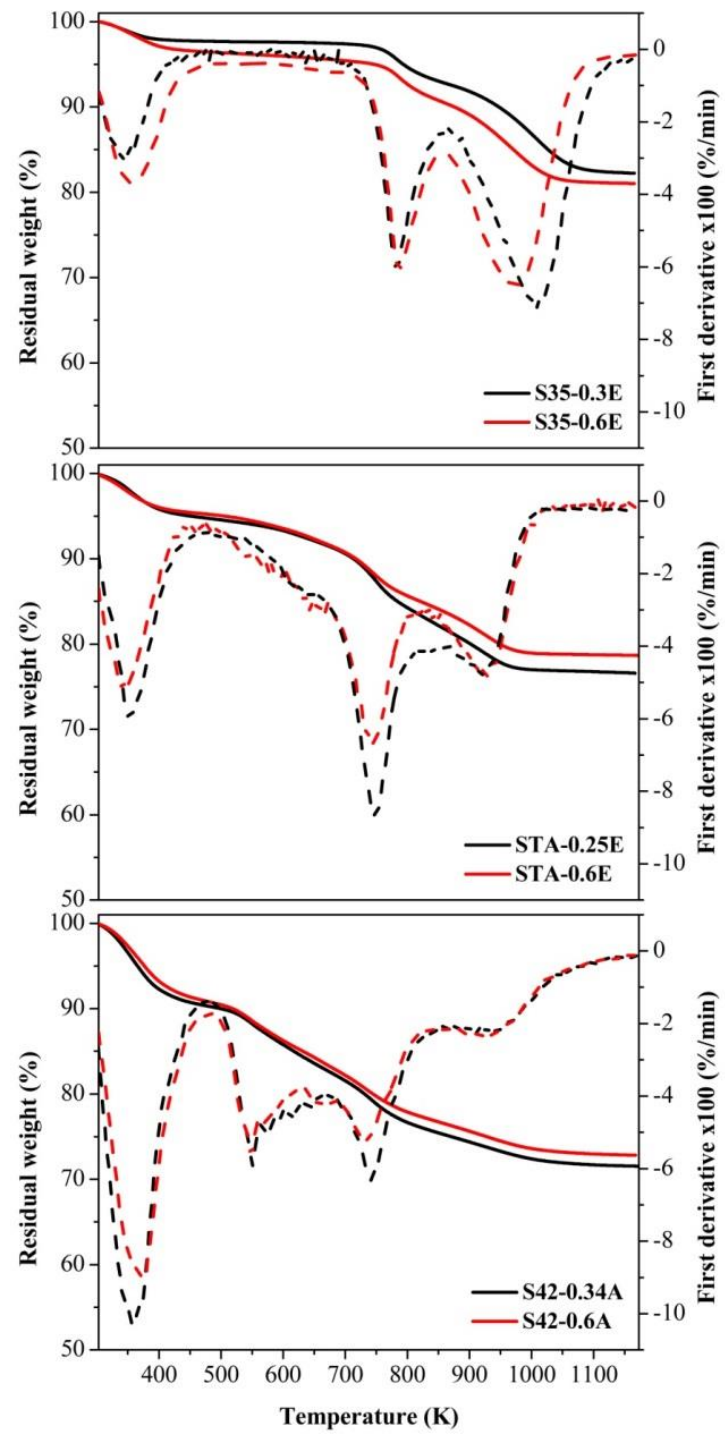

Figure 3. Thermogravimetric analyses of SAPO samples. The first derivative of the TG curve is shown in dashed lines.

All the calcined materials were analyzed by nitrogen adsorption-desorption in order to determine their adsorption capacity and textural properties. Surface area and pore volume values were calculated from the isotherms and are collected in Table 2. The isotherms show that all the samples are microporous, but a small non-microporous contribution is also registered, as shown by the continuous increase of the adsorbed volume with relative pressure above 0.05 (Fig. 4). In general, samples with more regular crystallites possess lower external (non-microporous) areas and volumes. Specifically in the case of SAPO-35, the crystallites are more regular when the samples are prepared with lower Si content, and that is reflected in their textural properties, being the sample with higher $\mathrm{Si} / \mathrm{Al}$ ratio $(\mathrm{S} 35-0.8 \mathrm{E})$ the one with higher ratio of multiple twinned crystals and also with higher external surface area and volume (Fig. 2, Table 2). The isotherm of this sample has a hysteresis cycle at high relative pressure that might be associated to the adsorption of nitrogen on the external surface of the irregular crystals. Similar trends are observed for both SAPO-42 and STA-7. The calculated values of non-microporous surface area and volume are higher for the samples prepared from gels with higher Si concentration. The isotherms of STA-7 and SAPO-42 samples show also hysteresis cycles that again are expected to be caused by the presence of intercrystalline spaces in the range of the meso-/macropores rather than by the presence of mesopores in the crystals (Fig. 4).

According to the silicon substitution mechanism SM2, the incorporation of a certain amount of Si into the AIPO framework should lead to an equivalent decrease of the number of $P$ atoms, whereas mechanism SM3 would result in the decrease of an $\mathrm{Al}$ atom and a $\mathrm{P}$ atom per every two Si atoms incorporated. Thus, from the chemical analysis of the SAPO materials it is possible to elucidate that the relative contribution of both silicon substitution mechanisms and, hence, the distribution of $\mathrm{Si}$ in the framework vary with the $\mathrm{Si}$ concentration in the samples. As shown in Table 1, both $\mathrm{P}$ and Al content decrease as the Si concentration increases. However, it is clearly seen that, as the amount of $\mathrm{Si}$ increases, the number of $\mathrm{P}$ atoms removed per every $\mathrm{Al}$ atom removed decreases. This means that high Si concentrations favour the incorporation of $\mathrm{Si}$ by pairs substituting $\mathrm{P}+\mathrm{Al}$ atoms in the structure $(\mathrm{SM} 3)$ versus the SM2 mechanism. Thus, it is expected that the proportion of the different Si environments in the solids changes with the silicon content, decreasing the fraction of $\mathrm{Si}$ atoms in Al-rich environments as the Si content increases.

Table 2. Textural properties of the calcined SAPO samples

\begin{tabular}{lcccc}
\hline \multirow{2}{*}{ Sample } & \multicolumn{2}{c}{ Surface area $\left(\mathrm{m}^{2} / \mathrm{g}\right)$} & \multicolumn{2}{c}{ Pore volume $\left(\mathrm{cm}^{3} / \mathrm{g}\right)$} \\
\cline { 2 - 5 } & $\mathrm{S}_{\text {BET }}$ & $\mathrm{S}_{\text {ext }}$ & $\mathrm{V}_{\text {micro }}$ & $V_{\text {ext }}$ \\
\hline S35-0.3E & 376 & 1 & 0.16 & 0.01 \\
S35-0.6E & 514 & 20 & 0.21 & 0.05 \\
S35-0.8E & 361 & 18 & 0.15 & 0.08 \\
STA-0.25E & 650 & 24 & 0.24 & 0.08 \\
STA-0.6E & 401 & 36 & 0.29 & 0.14 \\
STA-0.8E & 372 & 57 & 0.13 & 0.21 \\
S42-0.34A & 461 & 25 & 0.19 & 0.09 \\
S42-0.6A & 343 & 39 & 0.13 & 0.23 \\
\hline
\end{tabular}

Anyway, considering the relevance that the Si distribution has in the acidic properties of the material and, thus, in their catalytic properties in MTO, it is important to characterize properly the kind of environments formed and the distribution in the inorganic framework. With this aim, ${ }^{29} \mathrm{Si} \mathrm{CP} / \mathrm{MAS} \mathrm{NMR}$ spectroscopy was used to identify the different silicon environments present in the calcined samples and support the findings from elemental analysis about the distribution of the element in the lattice. The spectra of calcined SAPO-35 and STA7 samples with different Si content are presented in Fig. 5. Under the conditions used (reported in the experimental procedure section), it was not possible to obtain spectra of the sample S42-0.34A with sufficient quality due to the low Si concentration, so the comparison between the different $\mathrm{Si}$ environment formed in the samples with different Si content is not possible for SAPO-42 (Supporting Information, Fig. S2).

The same trends regarding the substitution mechanisms are observed for SAPO-35 and STA-7 samples. All the spectra registered consist of a broad signal in the range between -80 and $-120 \mathrm{ppm}$, which can be interpreted as a result of the 
overlapping of various resonances corresponding to different Si(nAl) environments.

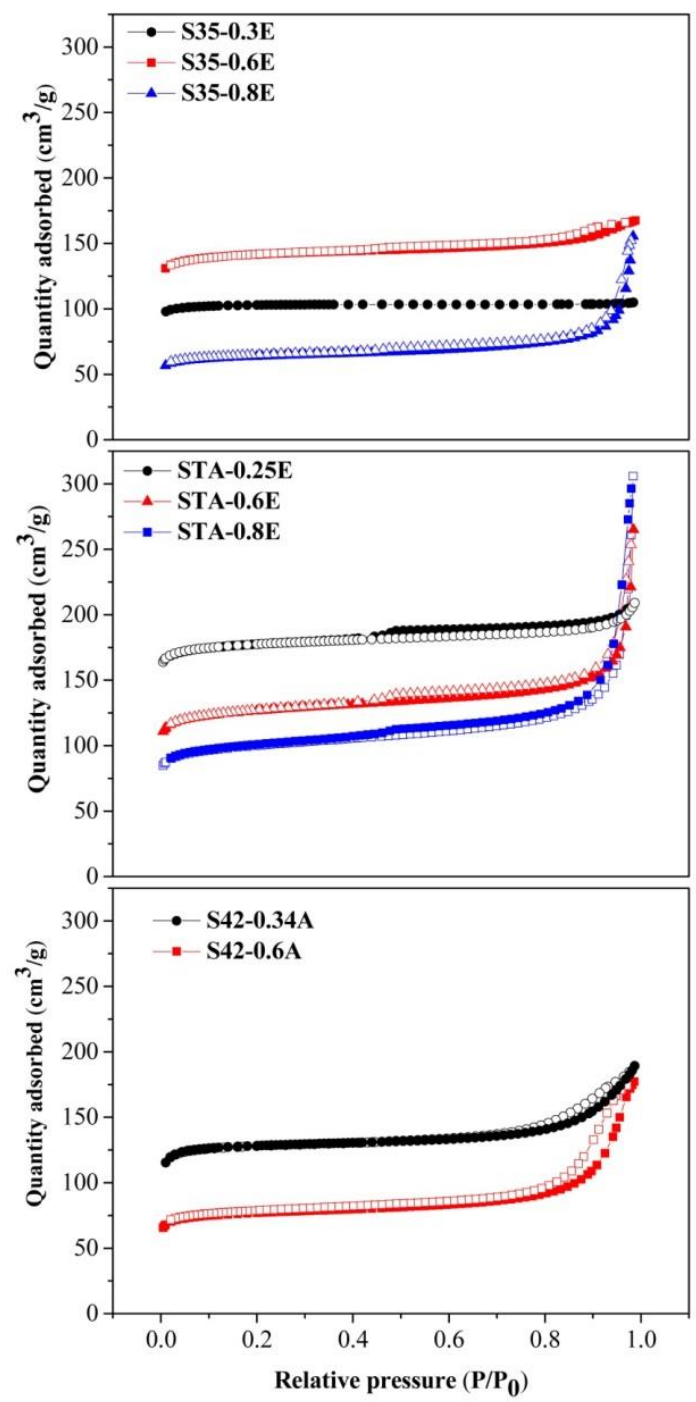

Figure 4. Nitrogen adsorption-desorption isotherms of calcined SAPO samples with different topology and Si content. Solid symbols correspond to adsorption data and empty symbols, to desorption.

The ${ }^{29} \mathrm{Si} \mathrm{CP} / \mathrm{MAS}$ NMR signal is shifted upfield as the number of $\mathrm{Al}$ atoms in the four neighbouring tetrahedra linked to the $\mathrm{Si}$ atom decreases. The spectra of the materials with lower $\mathrm{Si}$ content (S35-0.3E and STA-0.25E) display a main signal centred at $-89 \mathrm{ppm}$ that is typically associated to silicon atoms surrounded by four aluminium atoms in the second coordination sphere (Si(4Al)). In other words, it is again clear that low Si concentrations favour the incorporation of the metal by SM2 (substitution of one $\mathrm{P}$ atom by a Si atom in the AIPO framework). The spectra of the samples prepared with increasing Si concentrations in the synthesis gel show gradually higher intensity in the -95 to $-110 \mathrm{ppm}$ region, what indicates that, in these samples, Si incorporation occurs not only by the substitution of one $\mathrm{P}$ atom by a $\mathrm{Si}$ atom, but also by the simultaneous substitution of an Al-P pair (i.e., combined substitution mechanism $\mathrm{SM} 2+\mathrm{SM} 3)$, forming $\mathrm{Si}(3 \mathrm{Al}), \mathrm{Si}(2 \mathrm{Al})$, $\mathrm{Si}(1 \mathrm{Al})$ and $\mathrm{Si}(0 \mathrm{Al})$ species. The ${ }^{29} \mathrm{Si} \mathrm{CP} / \mathrm{MAS}$ NMR results reveal differences in the incorporation of Si mainly associated with the Si content in the sample. SM3 mechanism is favoured at high Si concentrations, and the incorporation of $\mathrm{Si}$ by pairs can eventually lead to the formation of $\mathrm{Si}$ islands in the framework (which contain $\mathrm{Si}$ atoms in $\mathrm{Si}(\mathrm{OAl})$ environments, i.e., not linked to $\mathrm{Al})$, which in turn result in a number of Brønsted acid sites (bridging $\mathrm{Si}-\mathrm{OH}-\mathrm{Al}$ hydroxyls) smaller than the number of $\mathrm{Si}$ atoms in the framework. This also causes a change of the proportions of the different $\mathrm{Si}(\mathrm{nAl})$ sites and, thus, on the average acid strength. It is therefore expected that the SAPO materials exhibit different acidity as the Si content increases, considering the differences observed in the NMR spectra.
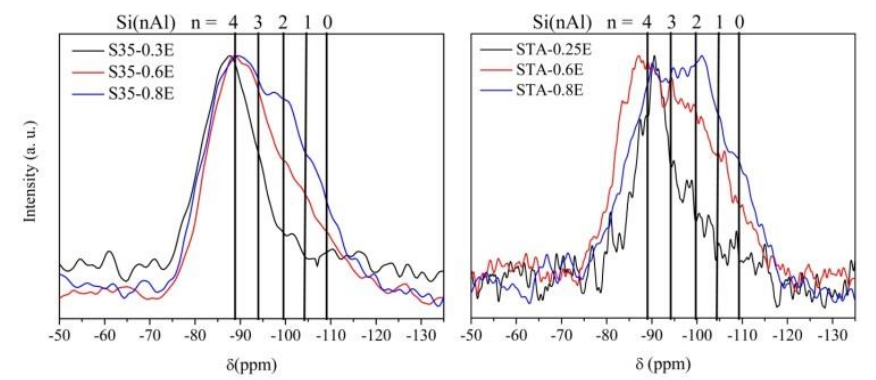

Figure 5. ${ }^{29} \mathrm{Si} \mathrm{CP} / \mathrm{MAS}$ NMR spectra of calcined SAPO-35 and STA-7 catalysts with different Si content.

It is clear that the combination of substitution mechanisms, that controls the final distribution of silicon in the materials, is greatly influenced by the amount of silicon in the synthesis gel. Nonetheless, it is important to keep in mind also that the topological features and the organic template used will control the incorporation and location of $\mathrm{Si}$ in the framework.

$\mathrm{NH}_{3}$-TPD analysis was used to study the effect of the silicon content and distribution on the acidic properties of the materials. The TPD profiles (Fig. 6) are substantially different for each topology, what is not surprising considering that the topological differences (size and shape of the cages and channels) as well as that the organic template used for the synthesis. As mentioned before, the topology may influence the incorporation of the dopants in the inorganic lattice. ${ }^{39}$ However, is it common for all the topologies that the sample with highest Si content shows a rather different desorption profile (Fig. 6). In the case of SAPO-35 materials, the sample with higher Si content (S35-0.8E) possesses a clearly lower density of acid sites than the other two samples, which profiles are rather similar. This observation can be explained in terms of the formation of silicon islands in the structure, giving rise to aluminosilicate domains in which just the Si located in the border of the island would give rise to Brønsted sites. On the other hand, sample S35-0.6E has a higher Si content than S35-0.3E, but the incorporation in the framework is not very different (Table 2, Fig. 5), so not surprisingly, the profile of both samples is similar, but the intensity of the desorption band is higher for sample S35-0.6E (Fig. 6). The same trend is followed in the case of SAPO-42 samples. However, this is not the case of STA-7 materials, in which the formation of environments other that $\mathrm{Si}(4 \mathrm{Al})$ in the samples with higher Si content is more prominent than in SAPO-35 (Fig. 5). The sample with higher Si content (STA$0.8 \mathrm{E}$ ), that is also the one in which the contribution of the Si environments formed by the incorporation of Si by pairs was higher, has a desorption maximum at rather high temperature. This can be due to the formation of $\mathrm{Si}$ islands with stronger sites in the border that requires higher temperature for the basic probe molecule to desorb. Regarding the samples with lower Si content (STA-0.25E and STA-0.6E), the opposite trend to that in SAPO-35 or SAPO-42 is observed. STA-7 has a high propensity to incorporate $\mathrm{Si}$ by pairs, so the contribution of different $\mathrm{Si}$ environments with few Al neighbours is enhanced even for the sample with an intermediate Si content (S35-0.6E). Thus, it is not surprising that in sample STA-0.6E, the intensity of the desorption peak in the $\mathrm{NH}_{3}$-TPD profile is a bit lower than in the case of STA-0.25E. 

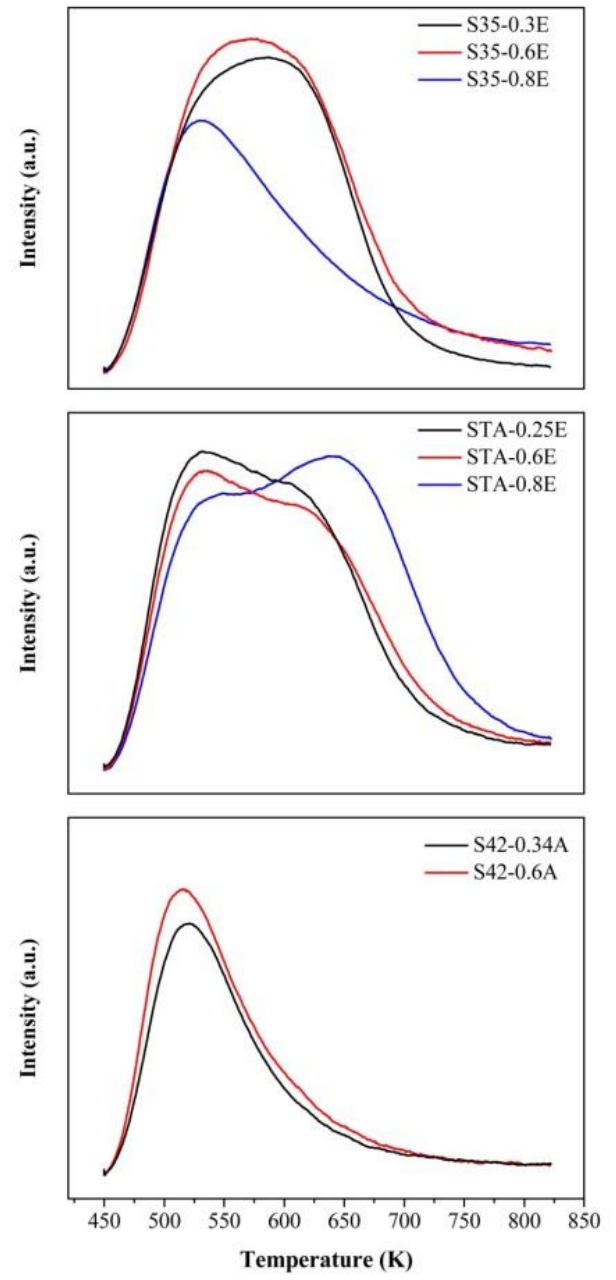

Figure 6. $\mathrm{NH}_{3}$-TPD profiles of the calcined SAPO samples with different topology and silicon content.

\section{Catalytic testing of the SAPO materials in the methanol to olefins} transformation.

The Si content of the SAPO samples is expected to affect their catalytic behaviour in the MTO transformation because of the influence that $\mathrm{Si}$ incorporation has in the described physicochemical properties of the materials, such as crystal size and morphology as well as concentration and strength of the acid sites that depend on the number and sitting of Si atoms in the AIPO framework. The catalytic performance of the SAPO materials synthesized with different topology and Si content was studied at $673 \mathrm{~K}$ under the experimental conditions described previously. In such conditions, all the samples reached full initial conversion of oxygenates (methanol and dimethyl ether) and a high selectivity to C2-C4 olefins (Fig. 7). The olefins distribution and stability of the catalysts were found to be influenced by $\mathrm{Si}$ content for the three topologies. However, the specific effect of the Si concentration on the catalytic performance is dependent on the topology, being also the pore structure a dominant parameter controlling the performance of each material. All the samples suffer a very fast deactivation under reaction conditions, hampering the interpretation of the deactivation curves. However, it is known from a previous contribution ${ }^{39}$ that SAPO-35 and STA-7 have a comparable deactivation profile similar to that of SAPO-34. At short reaction times the catalyst converts $100 \%$ of the oxygenated reactants and, after methanol breakthrough, a severe and fast loss in conversion is registered (Fig. 7). The methanol breakthrough can be more or less delayed depending on the stability of the catalyst. On the other hand, SAPO-42 deactivation behaviour has been found to be slightly different. In this case, the material is less active, what has been associated with the fact that there are some active centres located inside the sodalite cages and, therefore, are not accessible to methanol molecules. SAPO-42 deactivation curve does not show an initial period with $100 \%$ conversion followed by a fast deactivation, but a progressive loss of activity that ends in a constant low conversion rate. ${ }^{39}$

As described in the previous section, the variation in the $\mathrm{Si}$ concentration in the synthesis gel caused different modifications in the physicochemical properties for each topology, so the differences in the catalytic performance cannot be attributed to the same causes for all catalysts, but are the result of the combination of all the changes in the properties of the materials originated by the incorporation of increasing amounts of silicon.

First of all, the differences found in the distribution of olefins, can be easily attributed to the pore sizes of each material (SAPO-35<STA-7<SAPO-42) ${ }^{43}$. The formation of C4 olefins in enhance in the materials with larger pore sizes (SAPO-42 and STA-7), whereas ethylene selectivity is higher in SAPO-35.

In the case of SAPO-35, the sample with higher Si content is clearly the most stable one (Fig. 7). Considering the similar crystal sizes and values of external pore volume and surface area (Fig. 2, Table 2), the accessibility is not likely to be causing the observed enhancement in the life time of the catalyst, and it is more plausible that such enhancement has its origin in the lower density of acid sites (Fig. 6). Looking at the selectivities, there are small but significant differences to be pointed out. Ethylene is the main product for any value of Si content. In addition to that, the selectivity to ethylene increases as the Si content increases, whereas the selectivity to propylene is gradually lower. It is known that stronger acid sites favours the hydrogen transfer reactions enhancing the formation of aromatics, so this can be attributed to a higher contribution of the aromatic mechanistic cycle, which favours the formation of ethylene, in the stronger centres formed from non-isolated Si sites.
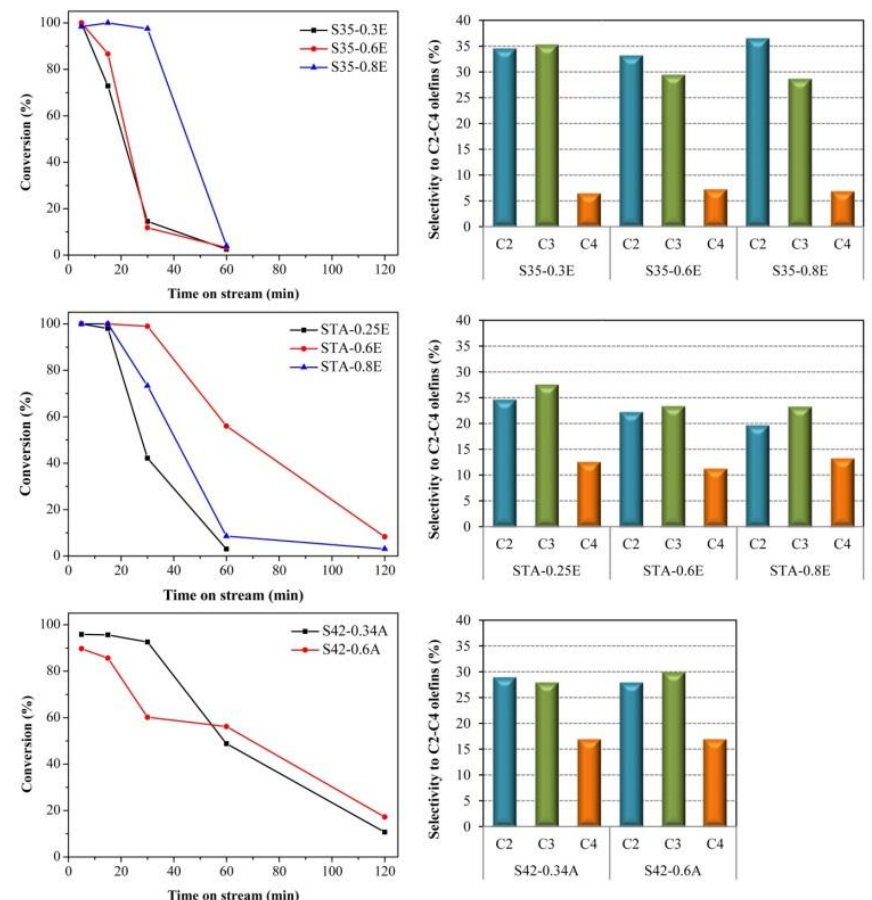

Figure 7. Left: Conversion of oxygenates (MeOH+DME) at $673 \mathrm{~K}$ as a function of time on stream over SAPO-35 (top), STA-7 (middle) and SAPO-42 catalysts (bottom) with different Si content. Right: Selectivity to short chain olefins compared at $100 \%$ conversion. 
The case of STA-7 is rather different. Comparing the samples with similar $\mathrm{NH}_{3}$-TPD profiles (STA-0.25E and STA-0.6E), the one with higher $\mathrm{Si}$ content also shows a higher value of external surface area (Table 2). This higher non-microporous surface can facilitate the diffusion of the products, hindering the formation of bulky molecules that can lead to a faster deactivation, and so happens in the case of STA-0.6E sample, that show an improved stability under reaction conditions (Fig. 7). Sample STA-0.8E has an even higher value of external surface area, so it would be expected to have a longer life time. However, stronger acid centres are formed in this sample (Fig. 6), and strong Brønsted centres favour the cyclization of the olefins and hydrogen transfer reactions that produce aromatics and alkanes as byproducts.

These aromatic molecules can easily evolve to polyaromatics, causing the faster deactivation of STA-0.8E in comparison with STA-0.6E. As aromatic molecules are unable to diffuse through the $8 \mathrm{R}$ pores of STA-7, it is possible to consider the selectivity to alkanes as a reliable indicator of the presence of aromatics in the material. This hypothesis is in good agreement with the lower selectivity to olefins displayed by the sample with stronger acid sites (STA-0.8E), and also with the relatively high production of alkenes (Supporting Information, Fig. S3). Looking at the product distribution, propylene is the main reaction product regardless of the acidity of the samples. The selectivity to C4 olefins is significantly higher compared to that obtained with SAPO-35. This observation can be attributed to the wider pores that STA-7 has, that allow the diffusion of larger molecules.

Finally, in the case of SAPO-42 materials, the sample with Si/AI ratio of 0.6 is slightly less active as catalyst (Fig. 7), what is surprising considering that this sample has higher external pore volume and surface area (Table 2 ) and also higher density of acid sites (Fig. 6). Nevertheless, the deactivation curve of both catalysts is similar. The total selectivity to $\mathrm{C} 2-\mathrm{C} 4$ olefins is also quite high with both catalysts, and in this case, just small variations are registered between the samples with different $\mathrm{Si}$ content. The selectivity to $\mathrm{C} 4$ olefins is even higher than that obtained with STA-7. This result is in agreement with our previous report ${ }^{39}$ where we associated the production of heavier olefins to the wider pores in the structure.

\section{Conclusions}

SAPO materials with three different topologies have been synthesized with different amounts of silicon in the synthesis gel in order to study the silicon incorporation for each topology as well as the effect of the Si content in the physicochemical and catalytic properties of the materials. Not only the silicon distribution but the silicon incorporation varies among the topologies, altering physicochemical properties that have a marked influence on the catalytic behaviour, such as acidity and crystal size and shape. In general, the presence of higher $\mathrm{Si}$ concentrations favours the formation of $\mathrm{Si}$ islands rather than isolated Si centres in the inorganic frameworks, and also leads to the formation of slightly less crystalline materials. The catalytic performance is mainly a result of the combined effect of the acidic and topological properties.

\section{Acknowledgements}

This work has been partially financed by the Spanish State Research Agency (Agencia Española de Investigación, AEI) and the European Regional Development Fund (Fondo Europeo de Desarrollo Regional, FEDER) through the Project MAT2016-
77496-R (AEI/FEDER, UE). IPH acknowledges CSIC for a PhD grant.

\section{References}

1 C.D. Chang, A.J. Silvestri, Journal of Catalysis, 1977, 47, 249.

2 M. Stöcker, Microporous and Mesoporous Materials, 1999, $29,3$.

3 U. Olsbye, S. Svelle, M. Bjørgen, P. Beato, T.V.W. Janssens, F. Joensen, S. Bordiga, K.P. Lillerud, Angewandte Chemie International Edition, 2012, 51, 5810.

4 Galadima, O. Muraza, Industrial Engeenering Chemical Research, 2015, 54, 4891.

5 D. Xiang, S. Yang, X. Liu, Z. Mai, Y. Qian, Chemical Engeenering Journal, 2014, 240, 45.

6 C.N. Hamelinck, A.P.C. Faaij, J. Power Sources, 2002, 111, 1.

7 G.A. Olah, A. Goeppert, G.K.S. Prakash, Journal of Organic Chemistry, 2009, 74, 487

8 C. Song, Catalysis Today, 2006, 115, 2.

9 P. Tian, Y. Wei, M. Ye, Z. Liu, ACS Catalysis, 2015, 5, 1922.

10 J.Q. Chen, A. Bozzano, B. Glover, T. Fuglerud, S. Kvisle, Catalysis Today, 2005, 106, 103.

11 T.V.W. Janssens, S. Svelle, U. Olsbye, Journal of Catalysis, $2013,308,122$

12 U. Olsbye, S. Svelle, K.P. Lillerud, Z.H. Wei, Y.Y. Chen, J.F. Li, J.G. Wang, W.B. Fan, Chemical Society Reviews, 2015, 44, 7155.

13 S. Müller, Y. Liu, M. Vishnuvarthan, X. Sun, A.C. van Veen, G.L. Haller, M. Sanchez-Sanchez, J.A. Lercher, Journal of Catalysis, 2015, 325, 48.

14 X. Sun, S. Mueller, Y. Liu, H. Shi, G.L. Haller, M. SanchezSanchez, A.C. van Veen, J.A. Lercher, Journal of Catalysis, 2014, 317, 185.

15 U. Olsbye, M. Bjørgen, S. Svelle, K.-P. Lillerud, S. Kolboe, Catalysis Today, 2005, 106, 108.

16 M. Westgård Erichsen, S. Svelle, U. Olsbye, Catalysis Today, 2013, 215, 216.

17 D. Rojo-Gama, S. Etemadi, E. Kirby, K.P. Lillerud, P. Beato, S. Svelle, U. Olsbye, Faraday Discussions, 197 (2016) 421-446.

18 M. Bjørgen, U. Olsbye, S. Kolboe, Journal of Catalysis, 2003, 215, 30.

19 M. Bjørgen, U. Olsbye, D. Petersen, S. Kolboe, Journal of Catalysis, 2004, 221, 1.

20 D. Chen, K. Moljord, A. Holmen, Microporous and Mesoporous Materials, 2012, 164, 239.

21 J.S. Martinez-Espin, M. Morten, T.V.W. Janssens, S. Svelle, P. Beato, U. Olsbye, Catalysis Science and Technology, 2017, DOI: $10.1039 / C 7 C Y 00129 K$.

22 D. Chen, K. Moljord, T. Fuglerud, A. Holmen, Microporous and Mesoporous Materials, 1999, 29, 191.

23 T. Álvaro-Muñoz, C. Márquez-Álvarez, E. Sastre, Applied Catalysis A-General, 2014, 472, 72.

24 T. Álvaro-Muñoz, C. Márquez-Álvarez, E. Sastre, Catalysis Today, 2013, 215, 208.

25 F. Wang, L. Sun, C. Chen, Z. Chen, Z. Zhang, G. Wei, X. Jiang, RSC Advances, 2014, 4, 46093.

26 L. Zhang, Y. Huang, Journal of Physical Chemistry C, 2016, 120, 25945.

27 T. Alvaro-Munoz, E. Sastre, C. Marquez-Alvarez, Catalysis Science and Technology, 2014, 4, 4330.

28 I. Pinilla-Herrero, C. Márquez-Álvarez, E. Sastre, Catalysis Today, 2016, 277, 29.

29 Y. Li, Y. Huang, J. Guo, M. Zhang, D. Wang, F. Wei, Y. Wang, Catalysis Today, 2014, 233, 2

30 Q. Sun, N. Wang, G. Guo, J. Yu, Chemical Communications, 2015, 51, 16397.

31 Z. Li, J. Martinez-Triguero, P. Concepcion, J. Yu, A. Corma, Physical Chemistry Chemical Physics, 2013, 15, 14670.

32 T. Álvaro-Muñoz, C. Márquez-Álvarez, E. Sastre, Catalysis Today, 2013, 213, 219.

33 S. Wilson, P. Barger, Microporous and Mesoporous Materials, 1999, 29, 117.

34 R. Martinez-Franco, Z. Li, J. Martinez-Triguero, M. Moliner, A. Corma, Catalysis Science and Technology, 2016, 6, 2796. 
35 S. del Val, T. Blasco, E. Sastre, J. Perez-Pariente, Journal of the Chemical Society, Chemical Communications, 1995, 731.

36 A.M. Prakash, S. Unnikrishnan, K.V. Rao, Applied Catalysis AGeneral, 1994, 110, 1.

37 S. Bordiga, L. Regli, C. Lamberti, A. Zecchina, M. Bjørgen, K.P. Lillerud, Journal of Physical Chemistry B, 2005, 109, 7724.

38 G. Sastre, D.W. Lewis, Journal of the Chemical Society, Faraday Transactions, 1998, 94, 3049.

39 I. Pinilla-Herrero, U. Olsbye, C. Márquez-Álvarez, E. Sastre, Journal of Catalysis, 2017, 352, 191.

40 A.M. Prakash, M. Hartmann, L. Kevan, Chemistry of Materials, 1998, 10, 932.

41 I. Pinilla-Herrero, L. Gómez-Hortigüela, C. Márquez-Álvarez, E. Sastre, Microporous and Mesoporous Materials, 2016, 219, 322.

42 M. Castro, R. Garcia, S.J. Warrender, A.M.Z. Slawin, P.A. Wright, P.A. Cox, A. Fecant, C. Mellot-Draznieks, N. Bats, Chemical Communications, 2007, 3470.

43 Ch. Baerlocher, L.B. McCusker, Database of Zeolite Structures: http://www.iza-structure.org/databases/

44 L. Sierra, C. Deroche, H. Gies, J.L. Guth, Microporous Materials, 1994, 3, 29.

45 B. Li, P. Tian, J. Li, J. Chen, Y. Yuan, X. Su, D. Fan, Y. Wei, Y. Qi, Z. Liu, Chinese Journal of Catalysis, 2013, 34, 798.

46 H. Zhao, S. Shi, J. Wu, Y. Ding, N. Li, Chinese Journal of Catalysis, 2016, 37, 227.

47 T. Álvaro-Muñoz, C. Márquez-Álvarez, E. Sastre, Catalysis Today, 2012, 179, 27. 